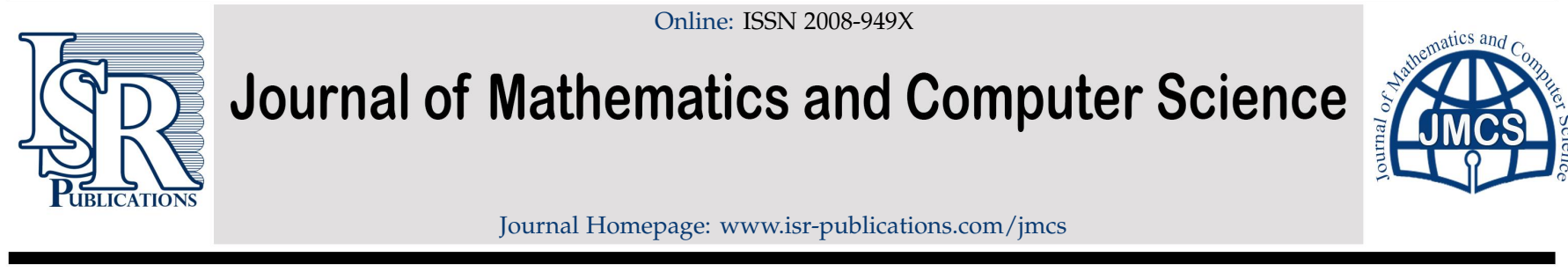

\title{
Presence and diversity of positive solutions for a Caputo- type fractional order nonlinear differential equation with an advanced argument
}

\author{
Md. Asaduzzaman ${ }^{\mathrm{a}, *}$, Adem Kilicman $^{\mathrm{b}}$, Md. Zulfikar Alic \\ ${ }^{a}$ Department of Mathematics, Islamic University, Kushtia, Bangladesh. \\ ${ }^{b}$ Department of Mathematics, Universiti Putra Malaysia, Selangor, Malaysia. \\ ${ }^{c}$ Department of Mathematics, University of Rajshahi, Rajshahi, Bangladesh.
}

\begin{abstract}
This article aims to construct the presence and diversity principles of minimum one or two positive solutions for a Caputotype fractional-order nonlinear differential equation (CFONLDE for short) with an advanced argument under three-point boundary value conditions (BVCs for short). Guo-Krasnoselskii's fixed point theorem and Fixed-point index theory in cone spaces are used to analyze this article. First, the Green's function of the corresponding boundary value problem for a linear fractional differential equation with an advanced argument has been established. Next, several essential properties of that Green's function have been proved. Finally, in cone spaces, some novel presence and diversity principles of minimum of one or two positive solutions for a CFONLDE with an advanced argument are obtained. To support the analytic proof, some particular examples are included.
\end{abstract}

Keywords: CFONLDE with an advanced argument, three-point boundary value conditions, Guo-Krasnoselskii fixed point theorem, fixed-point index theory, positive solution.

2020 MSC: 34A08, 34B18, 34K37.

(C)2021 All rights reserved.

\section{Introduction}

Literature may contain a huge number of applications of boundary value problem (BVP for short) with fractional order differential equations at different physical, mechanical, biological and chemical phenomena, for instance find the books of Kilbas et al. [27], Lakshmikantham et al. [28], Podlubny [32] and their cited references. Fractional order differential equations (FODEs for short) based model is more acceptable than integer order differential equations based model for its high degrees of freedom. From this context FODEs are obtaining a great consideration in the development of modern mathematics, for details one can visit the monographs of Ahmad and Nieto [4], Chang and Nieto [11], Goodrich [20] and Nieto [30] as well as their cited references.

\footnotetext{
${ }^{*}$ Corresponding author

Email addresses: masad_iu_math@yahoo.com (Md. Asaduzzaman), akilic@upm.edu.my (Adem Kilicman), alimath1964@gmail.com (Md. Zulfikar Ali)
}

doi: $10.22436 /$ jmcs.023.03.06

Received: 2020-07-10 Revised: 2020-09-07 Accepted: 2020-10-09 
During the last few decades diversity of positive solutions of different BVPs for fractional order nonlinear differential equation (FONLDE for short) has extensively considered by using various techniques, for instance see the articles of Agarwal et al. [2, 3], Afshari et al. [1], Asaduzzaman and Ali [5], Bai [8], Chen et al. [12], $\mathrm{Cu}$ et al. [13], Devi et al.[17], Sun et al. [34], and Torres [36] as well as for lower and upper solutions to the integro-differential and iterative hybrid type fractional differential equations see, Damag et al. [14] and Damag et al. [15] and for positive solutions of nonlinear dissipative type equations, see Asaduzzaman et al. [6].

On the other hand, Gupta [22] initiated the research on diversity of positive solutions to integer order nonlinear differential equation (IONLDE for short) with three-point BVCs. After Gupta [22] several researchers studied the diversity of positive solutions to IONLDE with three-point BVCs, for instance find the articles of Ma [29], Sun et al. [35], Webb [38] and Xu [39].

The IONLDE with advanced arguments have frequently been used by the researches associated to the field of mathematical physics, mechanical engineering and economics, for instance read the monographs of Agarwal et al. [3], Burton [10], and Jankowski [23, 25]. More about on the practical uses of IONLDE with advanced argument could be found in Augustynowicz et al. [7], Banaei et al. [9], El-Sayed [18], Jankowski [26], and Yang et al. [40]. From the applicable point of view, FONLDE with advanced argument is more significant than IONLDE with advanced argument. For this reason, now a days many researchers are interested to work on the solvability of FONLDE with advanced argument, for instance find the articles of Jankowski [24], Ntouyas et al. [31], Rizqan and Dhaigude [33], Wang et al.[37] and their cited references.

There is a small number of works related to presence of positive solutions of BVPs associated to FONLDE with advanced argument. Current progress on presence of positive solutions of FONLDE with advanced argument could be found in the articles of Ntouyas et al. [31], Rizqan and Dhaigude [33], and Wang et al. [37].

Inspired by the above-mentioned works on FONLDE with advanced argument, here we study the following CFONLDE with an advanced argument by means of Guo-Krasnoselskii's fixed point theorem [21] and Fixed-point index theory [16]:

$$
\left\{\begin{array}{l}
{ }^{c} D_{0^{+}}^{\gamma} y(x)+b(x) g(y(\varphi(x)))=0, x \in(0,1), 2<\gamma \leqslant 3 \\
y(0)=0, y^{\prime \prime}(0)=0, y(1)=\beta y(\xi)
\end{array}\right.
$$

wherever, ${ }^{c} D_{0^{+}}^{\gamma}$ represents Caputo's fractional differential operator of order and $\gamma \in(2,3], \xi \in(0,1), \beta \in$ $\left(0, \frac{1}{\xi}\right)$ and $g, b(x), \varphi(x)$ satisfy following hypothesis:

$\left(\mathrm{H}_{1}\right) \mathrm{g}:[0, \infty) \rightarrow[0, \infty)$ is continuous;

$\left(\mathrm{H}_{2}\right) \mathrm{b} \in \mathrm{L}^{\infty}[0,1]$ and $\exists \mathrm{m}>0$ such that (s.t. for short) $\mathrm{b}(\mathrm{x}) \geqslant \mathrm{m}$, a.e. (almost everywhere) for every $x \in[0,1]$

$\left(\mathrm{H}_{3}\right) \varphi:(0,1) \rightarrow(0,1)$ is continuous satisfying $x \leqslant \varphi(x) \leqslant 1$, for every $x \in(0,1)$.

From the work of Wang et al. [37], we observed that they considered the same problem as like (1.1) and established a presence principle of minimum one positive solution by means of Guo-Krasnoselskii's fixed point theorem. But in that work of Wang et al. [37], we devised a certain gap about the construction of Green's function of corresponding linear BVP of the nonlinear BVP given by (1.1). From this context here we reconsider the nonlinear BVP given by (1.1) and first construct the Green's function of corresponding linear BVP of the nonlinear BVP given by (1.1) and established the presence and diversity principles of minimum one or two positive solutions of nonlinear BVP given by (1.1) applying Guo-Krasnoselskii's fixed point theorem and Fixed-point index theory. Rest of this article is given by the following consecutive sections. Section 2 is used to introduce some basic facts and fundamental results. Section 3 is devoted to state and prove the presence and diversity principles of positive solutions of BVP given by (1.1). Finally, Section 4 is used to verify some illustrative examples. 


\section{Material and methods}

Here, we recall some preliminaries facts and fundamental results from the monographs of Deimling [16], Guo and Lakshmikantham [21], Kilbas et al. [27], Podlubny [32], Yang et al. [40], and establish some essential lemmas which are used as tools to establish main results of this article.

Definition 2.1. Let $\mathrm{g}:(0, \infty) \rightarrow \mathbf{R}$ (set of real numbers) be a continuous function. Then the RiemannLiouville fractional integral of order $\gamma>0$ is defined by

$$
\mathrm{I}_{0^{+}}^{\gamma} \mathrm{g}(x)=\frac{1}{\Gamma(\gamma)} \int_{0}^{x}(x-z)^{\gamma-1} \mathrm{~g}(z) \mathrm{d} z, x>0,
$$

where $\Gamma(\gamma)$ denotes Gamma function of $\gamma$.

Definition 2.2. Let $\mathrm{g}:(0, \infty) \rightarrow \mathbf{R}$ be a continuous function. Then the Riemann-Liouville fractional derivative of order $\gamma>0$ is defined by

$$
D_{0^{+}}^{\gamma} g(x)=\frac{1}{\Gamma(n-\gamma)}\left(\frac{d}{d x}\right)^{n} \int_{0}^{x}(x-z)^{n-\gamma-1} g(z) d z, n=[\gamma]+1,
$$

where $[\gamma]$ denotes integer part of real number $\gamma$.

Definition 2.3. Let $g:(0, \infty) \rightarrow \mathbf{R}$ be a continuous function. Then the Caputo's fractional derivative of order $\gamma>0$ is defined by

$$
{ }^{c} D_{0^{+}}^{\gamma} g(x)=\frac{1}{\Gamma(n-\gamma)} \int_{0}^{x}(x-z)^{n-\gamma-1} g^{(n)}(z) d z, n-1<\gamma \leqslant n, n=[\gamma]+1 .
$$

Lemma 2.4. Let $\mathrm{n}-1<\gamma \leqslant \mathrm{n}, \mathrm{y} \in \mathrm{C}^{\mathfrak{n}}[0,1]$. Then

$$
\mathrm{I}_{0^{+}}^{\gamma}{ }^{\mathrm{C}} \mathrm{D}_{0^{+}}^{\gamma} \mathrm{y}(\mathrm{x})=\mathrm{y}(\mathrm{x})-\mathrm{c}_{1}-\mathrm{c}_{2} x-\cdots-\mathrm{c}_{\mathrm{n}} x^{\mathrm{n}-1},
$$

whenever $\mathrm{c}_{1}, \mathrm{c}_{2}, \ldots, \mathrm{c}_{\mathrm{n}} \in \boldsymbol{R}$ and $\mathrm{n}=[\gamma]+1$.

Lemma 2.5. The relation $\mathrm{I}_{0^{+}}^{\gamma} \mathrm{I}_{0^{+}}^{\sigma} \mathrm{y}(\mathrm{x})=\mathrm{I}_{0^{+}}^{\gamma+\sigma}$ is valid in the following cases

$$
\operatorname{Re}(\sigma)>0, \operatorname{Re}(\gamma+\sigma)>0, y(x) \in \mathrm{L}^{1}(0,1) .
$$

Lemma 2.6. If $\beta \xi \neq 1$ and $h(x) \in C[0,1]$ for all $x \in(0,1)$, then for the $B V P$

$$
\left\{\begin{array}{l}
{ }^{C} D_{0^{+}}^{\gamma} y(x)+h(x)=0, x \in(0,1), 2<\gamma \leqslant 3, \\
y(0)=0, y^{\prime \prime}(0)=0, y(1)=\beta y(\xi),
\end{array}\right.
$$

there exists a unique solution

$$
y(x)=\int_{0}^{1} G_{1}(x, z) h(z) d z+\frac{\beta x}{1-\beta \xi} \int_{0}^{1} G_{2}(\xi, z) h(z) d z
$$

whenever

$$
\begin{aligned}
& \mathrm{G}_{1}(x, z)=\frac{1}{\Gamma(\gamma)} \begin{cases}x(1-z)^{\gamma-1}-(x-z)^{\gamma-1}, & 0 \leqslant z \leqslant x \leqslant 1, \\
x(1-z)^{\gamma-1}, & 0 \leqslant x \leqslant z \leqslant 1,\end{cases} \\
& \mathrm{G}_{1}(x, z)=\frac{1}{\Gamma(\gamma)} \begin{cases}\xi(1-z)^{\gamma-1}-(\xi-z)^{\gamma-1}, & 0 \leqslant z \leqslant \xi \leqslant 1, \\
\xi(1-z)^{\gamma-1}, & 0 \leqslant \xi \leqslant z \leqslant 1 .\end{cases}
\end{aligned}
$$


Proof. Combining the Lemma 2.4 and BVP given by (2.1), we obtain

$$
y(x)=-I_{0^{+}}^{\gamma} h(x)+c_{1}+c_{2} x+c_{3} x^{2},
$$

where $c_{1}, c_{2}, c_{3} \in \mathbf{R}$.

Taking derivative on both sides of (2.4) and applying the lemma 2.5, we get

$$
{ }^{c} D_{0^{+}}^{1} y(x)=-{ }^{c} D_{0^{+}}^{1} I_{0^{+}}^{\gamma} h(x)+c_{2}+2 c_{3} x=-{ }^{c} D_{0^{+}}^{1} I_{0^{+}}^{1} I_{0^{+}}^{\gamma-1} h(x)+c_{2}+2 c_{3} x,
$$

that is

$$
y^{\prime}(x)=-I_{0^{+}}^{\gamma-1} h(x)+c_{2}+2 c_{3} x
$$

and

$$
y^{\prime \prime}(x)=-I_{0^{+}}^{\gamma-2} h(x)+2 c_{3} .
$$

Applying the three-point boundary conditions of (2.1) in the equations (2.4), (2.5), and (2.6), we get

$$
\mathrm{c}_{1}=\mathrm{c}_{3}=0
$$

and

$$
c_{2}=\frac{1}{\Gamma(\gamma)} \cdot \frac{1}{1-\xi \beta}\left[\int_{0}^{1}(1-z)^{\gamma-1} h(z) d z-\beta \int_{0}^{\xi}(\xi-z)^{\gamma-1} h(z) d z\right] .
$$

Hence, the equation (2.4) yield that

$$
\begin{aligned}
\mathrm{y}(\mathrm{x})= & -\mathrm{I}_{0^{+}}^{\gamma} \mathrm{h}(\mathrm{x})+\frac{1}{\Gamma(\gamma)} \cdot \frac{1}{1-\xi \beta}\left[\int_{0}^{1}(1-z)^{\gamma-1} \mathrm{~h}(z) \mathrm{d} z-\beta \int_{0}^{\xi}(\xi-z)^{\gamma-1} \mathrm{~h}(z) \mathrm{d} z\right] \\
= & \frac{1}{\Gamma(\gamma)} \int_{0}^{x}(x-z)^{\gamma-1} \mathrm{~h}(z) \mathrm{d} z+\frac{x}{\Gamma(\gamma)(1-\xi \beta)} \int_{0}^{1}(1-z)^{\gamma-1} \mathrm{~h}(z) \mathrm{d} z-\frac{\beta x}{\Gamma(\gamma)(1-\xi \beta)} \int_{0}^{\xi}(\xi-z)^{\gamma-1} \mathrm{~h}(z) \mathrm{d} z \\
= & \frac{1}{\Gamma(\gamma)} \int_{0}^{x}(x-z)^{\gamma-1} \mathrm{~h}(z) \mathrm{d} z+\left[\frac{x}{\Gamma(\gamma)}+\frac{x \xi \beta}{\Gamma(\gamma)(1-\xi \beta)}\right] \int_{0}^{1}(1-z)^{\gamma-1} \mathrm{~h}(z) \mathrm{d} z \\
& -\frac{\beta x}{\Gamma(\gamma)(1-\xi \beta)} \int_{0}^{\xi}(\xi-z)^{\gamma-1} \mathrm{~h}(z) \mathrm{d} z \\
= & \frac{1}{\Gamma(\gamma)}\left[\int_{0}^{x}\left[x(1-z)^{\gamma-1}-(x-z)^{\gamma-1}\right] \mathrm{h}(z) \mathrm{d} z+\int_{x}^{1} x(1-z)^{\gamma-1} \mathrm{~h}(z) \mathrm{d} z\right] \\
& +\frac{\beta x}{\Gamma(\gamma)(1-\xi \beta)}\left[\int_{0}^{\xi}\left[\xi(1-z)^{\gamma-1}-(\xi-z)^{\gamma-1}\right] \mathrm{h}(z) \mathrm{d} z+\int_{\xi}^{1} \xi(1-z)^{\gamma-1} \mathrm{~h}(z) \mathrm{d} z\right]
\end{aligned}
$$

This proves the lemma.

Lemma 2.7. For Green's function $\mathrm{G}_{1}(\mathrm{x}, z)$ given by (2.3), following are true:

(i) $0 \leqslant \mathrm{G}_{1}(x, z) \leqslant \mathrm{G}_{1}(1, z)$;

(ii) $\min _{\eta \leqslant x \leqslant 1} G_{1}(x, z) \geqslant \eta G_{1}(1, z)$, where $\eta \in(0,1)$.

Proof.

(i) Since $2<\gamma \leqslant 3$, so for $0 \leqslant z \leqslant x \leqslant 1$, we have

$$
\mathrm{G}_{1}(x, z)=\frac{1}{\Gamma(\gamma)}\left[x(1-z)^{\gamma-1}-(x-z)^{\gamma-1}\right] \geqslant 0,
$$

and for $0 \leqslant x \leqslant z \leqslant 1$, we have

$$
\mathrm{G}_{1}(x, z)=\frac{1}{\Gamma(\gamma)} \cdot x(1-z)^{\gamma-1} \geqslant 0
$$


Thus, $\mathrm{G}_{1}(x, z) \geqslant 0$, for all $z \in[0,1]$.

Now, for both $0 \leqslant z \leqslant x \leqslant 1$ and $0 \leqslant x \leqslant z \leqslant 1$, we have $\frac{\partial G_{1}(x, z)}{\partial x}$ and this ensures that $G_{1}(x, z)$ is increasing on $x$. Therefore, we obtain

$$
0 \leqslant \mathrm{G}_{1}(x, z) \leqslant \mathrm{G}_{1}(1, z)
$$

(ii) Considering $\eta \leqslant x \leqslant 1$, we have

$$
\min _{\eta \leqslant x \leqslant 1} G_{1}(x, z)=G_{1}(\eta, z)
$$

where

$$
\mathrm{G}_{1}(\eta, z)=\frac{1}{\Gamma(\gamma)} \begin{cases}\eta(1-z)^{\gamma-1}-(\eta-z)^{\gamma-1}, & 0 \leqslant z \leqslant \eta \\ \eta(1-z)^{\gamma-1}, & \eta \leqslant z \leqslant 1\end{cases}
$$

Case-I: For $0 \leqslant z \leqslant \eta$, we have

$$
\min _{\eta \leqslant x \leqslant 1} G_{1}(x, z)=\frac{1}{\Gamma(\gamma)}\left(\eta(1-z)^{\gamma-1}-(\eta-z)^{\gamma-1}\right) .
$$

On the other hand,

$$
\eta G_{1}(1, z)=\frac{\eta(1-z)^{\gamma-1}}{\Gamma(\gamma)}-\frac{\eta(1-z)^{\gamma-1}}{\Gamma(\gamma)}=0
$$

Since $2<\gamma \leqslant 3$ and $\gamma-1>1, \eta \in(0,1) \Rightarrow \eta^{\gamma-1}<\eta, z \leqslant \eta \Rightarrow \frac{z}{\eta} \leqslant 1 \Rightarrow 1-\frac{z}{\eta} \geqslant 0, \eta<1 \Rightarrow 1<\frac{1}{\eta} \Rightarrow$ $-z \frac{1}{\eta}<-z \Rightarrow 1-\frac{z}{\eta}<1-z$, thus, we have $\left(1-\frac{z}{\eta}\right)^{\gamma-1}<(1-z)^{\gamma-1}$ and

$$
(\eta-z)^{\gamma-1}=\left(\eta\left(1-\frac{z}{\eta}\right)\right)^{\gamma-1}=\eta^{\gamma-1}\left(1-\frac{z}{\eta}\right)^{\gamma-1} \leqslant \eta\left(1-\frac{z}{\eta}\right)^{\gamma-1}<\eta(1-z)^{\gamma-1},
$$

i.e.,

$$
\eta(1-z)^{\gamma-1}-(\eta-z)^{\gamma-1} \geqslant 0
$$

From (2.7) and (2.9), we have

$$
\min _{\eta \leqslant x \leqslant 1} G_{1}(x, z) \geqslant 0 .
$$

Therefore, it follows from (2.8) and (2.10) that (ii) holds.

Case-II: For $\eta \leqslant z \leqslant 1$, we have

$$
\min _{\eta \leqslant x \leqslant 1} G_{1}(x, z)=\frac{\eta(1-z)^{\gamma-1}}{\Gamma(\gamma)}
$$

and

$$
\eta G_{1}(1, z)=\frac{\eta^{2}(1-z)^{\gamma-1}}{\Gamma(\gamma)}
$$

Since, $0<\eta<1$ thus, we have $\eta^{2}<\eta$. Hence,

$$
\frac{\eta^{2}(1-z)^{\gamma-1}}{\Gamma(\gamma)} \leqslant \frac{\eta(1-z)^{\gamma-1}}{\Gamma(\gamma)}
$$

Therefore, it follows from (2.11), (2.12), and (2.13) that (ii) holds.

Definition 2.8. A solution $y$ of a BVP is positive if it satisfies $y(x)>0$ for all $x \in(0,1)$.

Lemma 2.9. If $\eta \in(0,1), h(x):[0,1] \rightarrow[0, \infty)$ is continuous and $h(x) \geqslant 0$, then the BVP given by (2.1) retains a unique nonnegative solution $\mathrm{y}(\mathrm{x})$ and the inequality $\min _{\eta \leqslant x \leqslant 1} \mathrm{y}(\mathrm{x}) \geqslant \eta\|y\|$ holds. 
Proof. Taking double derivative on both sides of (2.2), we yield

$$
\mathrm{y}^{\prime \prime}=-\frac{1}{\Gamma(\gamma-2)} \int_{0}^{x}(x-z)^{\gamma-3} \mathrm{~h}(z) \mathrm{d} z \leqslant 0,
$$

which confirm that the graph of $y(x)$ is concavely downward on $(0,1)$. Furthermore, putting $x=1$ and $x=0$ in (2.2), we obtain

$$
y(1)=\frac{\beta}{\Gamma(\gamma)(1-\xi \beta)}\left[\int_{0}^{\xi}\left[\xi(1-z)^{\gamma-1}-(\xi-z)^{\gamma-1}\right] \mathrm{h}(z) \mathrm{d} z+\int_{\xi}^{1} \xi(1-z)^{\gamma-1} \mathrm{~h}(z) \mathrm{d} z\right] \geqslant 0,
$$

and

$$
y(0)=0 .
$$

Hence, $y$ is a unique nonnegative solution of BVP given by (2.1).

Now, applying Lemma 2.7 in (2.2), we get

$$
y(x) \leqslant \int_{0}^{1} G_{1}(1, z) h(z) d z+\frac{\beta}{1-\beta \xi} \int_{0}^{1} G_{2}(\xi, z) h(z) d z .
$$

So,

$$
\|y\| \leqslant \int_{0}^{1} G_{1}(1, z) h(z) d z+\frac{\beta}{1-\beta \xi} \int_{0}^{1} G_{2}(\xi, z) h(z) d z .
$$

Again, from (2.2) we have

$$
\begin{aligned}
y(x) & \geqslant \int_{0}^{1} \eta G_{1}(1, z) h(z) d z+\frac{\eta \beta}{1-\beta \xi} \int_{0}^{1} G_{2}(\xi, z) h(z) d z \\
& =\eta\left[\int_{0}^{1} G_{1}(1, z) h(z) d z+\frac{\beta}{1-\beta \xi} \int_{0}^{1} G_{2}(\xi, z) h(z) d z\right] .
\end{aligned}
$$

Hence, (2.14) and (2.15) yield that $y(x) \geqslant \eta\|y\|$ and this is the required inequality.

Definition 2.10. Let $(B,\|\cdot\|)$ be a Banach space and $K \subseteq B$ which is nonempty, closed, and convex. Then we define $\mathrm{K}$ as a cone on $\mathrm{B}$ if it satisfies the following properties:

(i) $\lambda c \in K$ for $c \in K, \lambda>0$;

(ii) $\mathrm{c},-\mathrm{c} \in \mathrm{K}$ implies $\mathrm{c}=\theta$,

where $\theta$ denotes the null element of $B$.

Throughout this paper, we suppose that $B=C[0,1]$ and norm is defined as $\|y\|=\max _{0 \leqslant x \leqslant 1} y(x)$.

Theorem 2.11 (Guo-Krasnoselskii's fixed point Theorem). Let B be a Banach space and $\mathrm{K} \subseteq \mathrm{B}$ be a cone on B. Suppose that $\Omega_{1}$ and $\Omega_{2}$ are two open subsets of $\mathrm{B}$ with $0 \in \Omega_{1}, \bar{\Omega}_{1} \subseteq \Omega_{2}$ and $\mathrm{T}: \mathrm{K} \cap\left(\bar{\Omega}_{2} \backslash \Omega_{1}\right) \rightarrow \mathrm{K}$ is a completely continuous map with

(i) $\|\mathrm{T} y\| \leqslant\|y\|$, for all $\mathrm{y} \in \mathrm{K} \cap \partial \Omega_{1}$ and $\|\mathrm{T} y\| \geqslant\|y\|$, for all $\mathrm{y} \in \mathrm{K} \cap \partial \Omega_{2} ;$ or

(ii) $\|\mathrm{T} y\| \geqslant\|y\|$, for all $\mathrm{y} \in \mathrm{K} \cap \partial \Omega_{1}$ and $\|\mathrm{T} y\| \leqslant\|y\|$, for all $\mathrm{y} \in \mathrm{K} \cap \partial \Omega_{2}$.

Then $\mathrm{T}$ has a fixed point in $\mathrm{K} \cap\left(\bar{\Omega}_{2} \backslash \Omega_{1}\right)$.

Now, we give a brief description on fixed-point index using the following lemma.

Lemma 2.12. Let $\mathrm{K}$ be a closed convex subset of a Banach space $\mathrm{B}$ and let $\mathrm{D}$ be a bounded open set s.t. $\mathrm{D}_{\mathrm{K}}=$ $\mathrm{D} \cap \mathrm{K} \neq \emptyset$. Let $\mathrm{T}: \overline{\mathrm{D}}_{\mathrm{K}} \rightarrow \mathrm{K}$ be a compact map. Suppose that $\mathrm{T} \mathrm{x} \neq \mathrm{x}$ for all $\mathrm{x} \in \partial \mathrm{D}_{\mathrm{K}}$ (boundary of $\mathrm{D}_{\mathrm{K}}$ ). 
(i) If $\mathrm{I}\left(\mathrm{T}, \mathrm{D}_{\mathrm{K}}, \mathrm{K}\right) \neq 0$, then $\mathrm{T}$ has a fixed point in $\mathrm{D}_{\mathrm{K}}$.

(ii) If $\mathrm{y} \in \mathrm{D}_{\mathrm{K}}$, then $\mathrm{I}\left(\hat{\mathrm{y}}, \mathrm{D}_{\mathrm{K}}, \mathrm{K}\right)=1$, where $\hat{\mathrm{y}}(\mathrm{x})=\mathrm{y}$ for $\mathrm{x} \in \overline{\mathrm{D}}_{\mathrm{K}}$.

(iii) Let $\mu:[0,1] \times \bar{D}_{K} \rightarrow K$ be a compact map s.t. $x \neq \mu(t, x)$ for $x \in \partial D_{K}$ and $t \in[0,1]$. Then

$$
\mathrm{I}\left(\mu(0, \cdot), \mathrm{D}_{\mathrm{K}}, \mathrm{K}\right)=\mathrm{I}\left(\mu(1, \cdot), \mathrm{D}_{\mathrm{K}}, \mathrm{K}\right) .
$$

(iv) If $\mathrm{U}_{1}, \mathrm{U}_{2}$ are disjoint relatively open subsets of $\mathrm{D}_{\mathrm{K}}$ s.t. $\mathrm{T} x \neq \mathrm{x}$ for $\mathrm{x} \in \overline{\mathrm{D}}_{\mathrm{K}} \backslash\left(\mathrm{U}_{1} \cup \mathrm{U}_{2}\right)$, then

$$
\mathrm{I}\left(\mathrm{T}, \mathrm{D}_{\mathrm{K}}, \mathrm{K}\right)=\mathrm{I}\left(\mathrm{T}, \mathrm{U}_{1}, \mathrm{~K}\right)+\mathrm{I}\left(\mathrm{T}, \mathrm{U}_{2}, \mathrm{~K}\right)
$$

where $\mathrm{I}\left(\mathrm{T}, \mathrm{U}_{\mathrm{j}}, \mathrm{K}\right)=\mathrm{I}\left(\mathrm{T} \backslash \overline{\mathrm{U}}_{\mathrm{j}}, \mathrm{U}_{\mathrm{j}}, \mathrm{K}\right), \mathrm{j}=1,2$.

Now, we state fixed-point index theory from a book of Deimling [16].

Theorem 2.13 (Fixed-point index theory). Let $\mathrm{B}$ be a Banach space and $\mathrm{K} \subseteq \mathrm{B}$ be a cone in $\mathrm{B}$. For $\mathrm{r}>0$, define $\mathrm{K}_{\mathrm{r}}=\{\mathrm{y} \in \mathrm{K}:\|\mathrm{y}\| \leqslant \mathrm{r}\}$ and assume that $\mathrm{T}: \mathrm{K}_{\mathrm{r}} \rightarrow \mathrm{K}$ is a completely continuous operator s.t. $\mathrm{Ty} \neq \mathrm{y}$ for $\mathrm{y} \in \partial \mathrm{K}_{\mathrm{r}}$. Then the following hold:

(1) If $\|\mathrm{T} y\| \leqslant\|y\|$, for all $\mathrm{y} \in \partial \mathrm{K}_{\mathrm{r}}$, then $\mathrm{I}\left(\mathrm{T}, \mathrm{K}_{\mathrm{r}}, \mathrm{K}\right)=1$;

(2) If $\|\mathrm{T} y\| \geqslant\|y\|$, for all $\mathrm{y} \in \partial \mathrm{K}_{\mathrm{r}}$, then $\mathrm{I}\left(\mathrm{T}, \mathrm{K}_{\mathrm{r}}, \mathrm{K}\right)=0$,

where $\mathrm{I}$ is the point index on $\mathrm{K}$.

Remark 2.14. According to Lemma 2.6, we can convert the BVP given by (1.1) to

$$
y(x)=\int_{0}^{1} G_{1}(x, z) b(z) g(y(\varphi(z))) d z+\frac{\beta x}{1-\beta \xi} \int_{0}^{1} G_{2}(\xi, z) b(z) g(y(\varphi(z))) d z,
$$

where $G_{1}(x, z)$ and $G_{2}(\xi, z)$ are given by (2.3).

Obviously, $y=y(x)$ for all $x \in(0,1]$, is a solution of the BVP given by (1.1), if and only if it is a solution of integral equation (2.16).

Furthermore, if we define a cone $\mathrm{K}$ on $\mathrm{B}$ in the following way

$$
K=\left\{y \in B: y(\varphi(x)) \geqslant 0, \min _{\eta \leqslant x \leqslant 1} y(\varphi(x)) \geqslant \eta\|y\|, \eta \in(0,1)\right\},
$$

and the operator $\mathrm{T}: \mathrm{K} \rightarrow \mathrm{B}$ in the following way

$$
\operatorname{Ty}(\varphi(x))=\int_{0}^{1} G_{1}(x, z) b(z) g(y(\varphi(z))) d z+\frac{\beta x}{1-\beta \xi} \int_{0}^{1} G_{2}(\xi, z) b(z) g(y(\varphi(z))) d z,
$$

then it is easy to prove that the BVP given by (1.1) may have a solution $y(x)$ if and only if the integral operator $\mathrm{T}$ may exists a fixed point $\mathrm{y}(\mathrm{x})$.

Lemma 2.15. Integral operator $\mathrm{T}$ define by (2.18) is completely continuous and $\mathrm{T}(\mathrm{K}) \subseteq \mathrm{K}$, where $\mathrm{K}$ is a cone on $\mathrm{C}[0,1]$ defined by (2.17).

Proof. By Lemma 2.9, it is obvious that $\mathrm{T}(\mathrm{K}) \subseteq \mathrm{K}$. According to the definition of $\mathrm{G}_{1}(x, z), \mathrm{G}_{2}(\xi, z)$ and $b(x) g(y(\varphi(x)))$, it is clear that $T$ is continuous.

Suppose that $\Omega$ is a bounded subset of $K$, then we get $\|y(\varphi(x))\| \leqslant M$ for all $y(\varphi(x)) \in \Omega$ and $M>0$.

Now, if we set $L=\max _{0 \leqslant y(\varphi(x)) \leqslant M}|g(y(\varphi(x)))|$, then for $y(\varphi(x)) \in \Omega$, Lemmas 2.7 and 2.9 give us

$$
\begin{aligned}
& |\operatorname{Ty}(\varphi(x))| \\
& \leqslant \frac{1}{\Gamma(\gamma)} \int_{0}^{1}(1-z)^{\gamma-1}|\mathrm{~b}(z)||\mathrm{g}(\mathrm{y}(\varphi(z)))| \mathrm{d} z+\frac{\beta \xi}{\Gamma(\gamma)(1-\beta \xi)} \int_{0}^{1}(1-z)^{\gamma-1}|\mathrm{~b}(z)||\mathrm{g}(\mathrm{y}(\varphi(z)))| \mathrm{d} z \\
& \leqslant\left[\frac{\mathrm{L}\|\mathrm{b}\|_{\infty}}{\Gamma(\gamma)}+\frac{\beta \xi \cdot \mathrm{L}\|\mathrm{b}\|_{\infty}}{\Gamma(\gamma)(1-\beta \xi)}\right] \int_{0}^{1}(1-z)^{\gamma-1} \mathrm{~d} z \\
& =\frac{\mathrm{L}\|\mathrm{b}\|_{\infty}}{\Gamma(\gamma)} \cdot \frac{1}{1-\beta \xi} \int_{0}^{1}(1-z)^{\gamma-1} \mathrm{~d} z=\frac{\mathrm{L}\|\mathrm{b}\|_{\infty}}{\Gamma(\gamma+1)} \cdot \frac{1}{1-\beta \xi}=l(\text { say }) .
\end{aligned}
$$


This proves that $T(\Omega)$ is bounded. Again, for $y(\varphi(x)) \in \Omega, x_{1}, x_{2} \in[0,1]$ with $x_{1}<x_{2}$, we have

$$
\begin{aligned}
\left|\operatorname{Ty}\left(\varphi\left(x_{2}\right)\right)-\operatorname{Ty}\left(\varphi\left(x_{1}\right)\right)\right| & \leqslant L\|b\|_{\infty} \cdot\left[\int_{0}^{1}\left[G_{1}(1, z)-G_{1}(1, z)\right] d z+\frac{\beta\left|x_{2}-x_{1}\right|}{1-\beta \xi} \cdot \int_{0}^{1} G_{2}(\xi, z) d z\right] \\
& =L\|b\|_{\infty} \cdot \frac{\beta \xi\left|x_{2}-x_{1}\right|}{\Gamma(\gamma)(1-\beta \xi)} \cdot \int_{0}^{1}(1-z)^{\gamma-1} \mathrm{~d} z \\
& =L\|b\|_{\infty} \cdot \frac{\beta \xi\left|x_{2}-x_{1}\right|}{\Gamma(\gamma+1)(1-\beta \xi)} \leqslant l \cdot\left|x_{2}-x_{1}\right| .
\end{aligned}
$$

Hence, by an application of Arzela-Ascoli theorem which is taken from Fréchet [16], it is obvious that the continuity of $\mathrm{T}$ is complete.

Throughout this paper, we suppose that

$$
g_{c}=\lim _{y \rightarrow c} \inf \frac{g(y(\varphi(x)))}{y(\varphi(x))}, g^{d}=\lim _{y \rightarrow d} \sup \frac{g(y(\varphi(x)))}{y(\varphi(x))},
$$

where $\mathrm{c}, \mathrm{d}=0+$ or $\infty$,

$$
M_{1}=\eta^{2} m\left[\int_{\eta}^{1} G_{1}(1, z) d z+\frac{\beta}{1-\beta \xi} \int_{\eta}^{1} G_{2}(\xi, z) d z\right]
$$

and

$$
M_{2}=\|b\|_{\infty}\left[\int_{0}^{1} G_{1}(1, z) d z+\frac{\beta}{1-\beta \xi} \int_{0}^{1} G_{2}(\xi, z) d z\right] .
$$

\section{Main results}

Here, we state and prove three theorems which represents main outcomes of this article. Before starting these theorems, we have required some assumptions which are as follows:

$\left(\mathrm{A}_{1}\right) \mathrm{g}^{0+}=0$ and $\mathrm{g}_{\infty}=\infty$;

$\left(\mathrm{A}_{2}\right) \mathrm{g}_{0+}=\infty$ and $\mathrm{g}^{\infty}=0$;

$\left(\mathrm{A}_{3}\right) \mathrm{g}_{0+}=\infty$ and $\mathrm{g}_{\infty}=\infty$;

( $\left.\mathrm{A}_{4}\right) \mathrm{g}^{0+}=0$ and $\mathrm{g}^{\infty}=0$;

$\left(\mathrm{A}_{5}\right) 0 \leqslant \mathrm{~g}^{0+}<\mathrm{M}_{2}^{-1}$ and $\mathrm{M}_{1}^{-1}<\mathrm{g}_{\infty} \leqslant \infty$;

( $\left.\mathrm{A}_{6}\right) \mathrm{M}_{1}^{-1}<\mathrm{g}_{0+} \leqslant \infty$ and $0 \leqslant \mathrm{~g}^{\infty}<\mathrm{M}_{2}^{-1}$;

$\left(\mathrm{A}_{7}\right) \mathrm{g}(\mathrm{y}(\varphi(x)))<\mathrm{M}_{2}^{-1} \rho$ and $0<y(\varphi(x)) \leqslant \rho$, for all $\rho>0$;

(A 8$) g(y(\varphi(x)))>M_{1}^{-1} \rho$ and $\rho<y(\varphi(x)) \leqslant \frac{\rho}{\beta}$, for all $\rho>0$.

Now, we are ready to present our main results.

Theorem 3.1. Suppose that $\left(\mathrm{H}_{1}\right),\left(\mathrm{H}_{2}\right)$, and $\left(\mathrm{H}_{3}\right)$ are satisfied. If one of the assumptions $\left(\mathrm{A}_{1}\right),\left(\mathrm{A}_{2}\right),\left(\mathrm{A}_{5}\right),\left(\mathrm{A}_{6}\right)$ holds, then for the BVP given by (1.1) exists minimum a positive solution.

Proof.

Case-I: When $\left(A_{1}\right)$ holds.

Since, $g^{0+}=0, \exists$ a positive constant $h_{1}$ s.t. $g(y(\varphi(x))) \leqslant \delta y(\varphi(x))$, wherever $0<y(\varphi(x)) \leqslant h_{1}$ and $\delta>0$.

Then for $y(\varphi(x)) \in K \cap \partial \Omega_{1}$, where $\Omega_{1}=\left\{y(\varphi(x)) \in B:\|y(\varphi(x))\|<h_{1}\right\}$, we get

$$
\operatorname{Ty}(\varphi(x))=\int_{0}^{1} G_{1}(x, z) b(z) g(y(\varphi(z))) d z+\frac{\beta x}{1-\beta \xi} \int_{0}^{1} G_{2}(\xi, z) b(z) g(y(\varphi(z))) d z
$$




$$
\begin{aligned}
& \leqslant \int_{0}^{1} G_{1}(1, z) b(z) g(y(\varphi(z))) d z+\frac{\beta}{1-\beta \xi} \int_{0}^{1} G_{2}(\xi, z) b(z) g(y(\varphi(z))) d z \\
& \leqslant \int_{0}^{1} G_{1}(1, z)\|b\|_{\infty} \delta y(\varphi(z)) d z+\frac{\beta}{1-\beta \xi} \int_{0}^{1} G_{2}(\xi, z)\|b\|_{\infty} \delta y(\varphi(z)) d z \\
& \leqslant \delta\left[\|b\|_{\infty}\left(\int_{0}^{1} G_{1}(1, z) d z+\frac{\beta}{1-\beta \xi} \int_{0}^{1} G_{2}(\xi, z) d z\right)\right]\|y(\varphi(x))\| \\
& =\delta M_{2}\|y(\varphi(x))\| .
\end{aligned}
$$

Now, if $\delta M_{2} \leqslant 1$ and taking the maximum in $0 \leqslant x \leqslant 1$, we yield that

$$
\|\mathrm{Ty}(\varphi(x))\| \leqslant\|y(\varphi(x))\| .
$$

Again, since $g_{\infty}=\infty, \exists$ a positive constant $\overline{h_{2}}$ s.t. $g(y(\varphi(x))) \geqslant \delta_{1} y(\varphi(x))$, where $\overline{h_{2}} \leqslant y(\varphi(x)), x \in[\eta, 1]$ and $\delta>0$.

For $y(\varphi(x)) \in K \cap \partial \Omega_{2}$, where $\Omega_{2}=\left\{y(\varphi(x)) \in B:\|y(\varphi(x))\|<h_{2}\right\}$ and $h_{2}$ is maximum of $2 h_{1}$ and $\frac{h_{2}}{\eta}$. Then $y(\varphi(x)) \in K \cap \partial \Omega_{2}$ implies that $\min _{\eta \leqslant x \leqslant 1} y(\varphi(x)) \geqslant \eta\|y(\varphi(x))\|=\eta h_{2}>\overline{h_{2}}$ and

$$
\begin{aligned}
\operatorname{Ty}(\varphi(x)) & =\int_{0}^{1} G_{1}(x, z) b(z) g(y(\varphi(z))) d z+\frac{\beta x}{1-\beta \xi} \int_{0}^{1} G_{2}(\xi, z) b(z) g(y(\varphi(z))) d z \\
& \geqslant \int_{\eta}^{1} G_{1}(x, z) b(z) g(y(\varphi(z))) d z+\frac{\beta x}{1-\beta \xi} \int_{\eta}^{1} G_{2}(\xi, z) b(z) g(y(\varphi(z)) d z \\
& \geqslant \int_{\eta}^{1} \eta G_{1}(1, z) m \delta_{1} y(\varphi(z)) d z+\frac{\beta \eta}{1-\beta \xi} \int_{\eta}^{1} G_{2}(\xi, z) m \delta_{1} y(\varphi(z)) d z \\
& \geqslant \int_{\eta}^{1} \eta^{2} G_{1}(1, z) m \delta_{1}\|y(\varphi(z))\| d z+\frac{\beta \eta^{2}}{1-\beta \xi} \int_{\eta}^{1} G_{2}(\xi, z) m \delta_{1}\|y(\varphi(z))\| d z \\
& \geqslant \delta_{1}\left[\eta^{2} m\left(\int_{\eta}^{1} G_{1}(1, z) d z+\frac{\beta}{1-\beta \xi} \int_{\eta}^{1} G_{2}(\xi, z) d z\right)\right]\|y(\varphi(x))\| \\
& =\delta_{1} M_{1}\|y(\varphi(x))\| .
\end{aligned}
$$

Now, if $\delta_{1} M_{1} \geqslant 1$ and taking the maximum in $0 \leqslant x \leqslant 1$, then

$$
\|\operatorname{Ty}(\varphi(x))\| \geqslant\|y(\varphi(x))\| \text {. }
$$

Therefore, Theorem 2.11 and Lemmas 2.9 and 2.15, yield a positive fixed point of $\mathrm{T}$ in $\mathrm{K} \cap\left(\bar{\Omega}_{2} \backslash \Omega_{1}\right)$. Hence for the BVP given by (1.1) exists minimum a positive solution.

Case-II: When $\left(\mathrm{A}_{2}\right)$ holds.

In this case, since $g_{0_{+}}=\infty$, then same case arises as like second part of Case-I, so here we omit it.

Again, since $g^{\infty}=0, \exists$, a positive constant $\bar{h}_{2}$ s.t. $g(y(\varphi(x))) \leqslant \lambda y(\varphi(x))$, where $y(\varphi(x)) \geqslant \bar{h}_{2}$, and $\lambda>0$ satisfies $\lambda M_{2} \leqslant 1$. Now, if $g$ is bounded, $\exists$ a positive L s.t. $g(y(\varphi(x)))<L$,

$$
\Omega_{2}=\left\{y(\varphi(x)) \in B:\|y(\varphi(x))\|<h_{2}\right\},
$$

where $h_{2}=\max \left\{2 h_{1}, L M_{2}\right\}$. If $y(\varphi(x)) \in K \cap \partial \Omega_{2}$, then by Lemma 2.7, we get

$$
\begin{aligned}
\operatorname{Ty}(\varphi(x)) & =\int_{0}^{1} \mathrm{G}_{1}(x, z) \mathrm{b}(z) \mathrm{g}(\mathrm{y}(\varphi(z))) \mathrm{d} z+\frac{\beta x}{1-\beta \xi} \int_{0}^{1} \mathrm{G}_{2}(\xi, z) \mathrm{b}(z) g(y(\varphi(z))) \mathrm{d} z \\
& \leqslant \int_{0}^{1} \mathrm{G}_{1}(1, z) \mathrm{b}(z) \mathrm{g}(\mathrm{y}(\varphi(z))) \mathrm{d} z+\frac{\beta}{1-\beta \xi} \int_{0}^{1} \mathrm{G}_{2}(\xi, z) \mathrm{b}(z) g(y(\varphi(z))) \mathrm{d} z \\
& \leqslant \int_{0}^{1} \mathrm{G}_{1}(1, z)\|\mathrm{b}\|_{\infty} \mathrm{Ld} z+\frac{\beta}{1-\beta \xi} \int_{0}^{1} \mathrm{G}_{2}(\xi, z)\|\mathrm{b}\|_{\infty} \mathrm{Ld} z \\
& =\mathrm{LM}_{2} \leqslant \mathrm{~h}_{2}=\|\mathrm{y}(\varphi(x))\| .
\end{aligned}
$$


Hence,

$$
\|\mathrm{Ty}(\varphi(x))\| \leqslant\|y(\varphi(x))\| .
$$

And, if $g$ is unbounded, then by our hypothesis $\left(H_{1}\right)$, there exists $h_{2}>0$ s.t. $h_{2}>\max \left\{2 h_{1}, \frac{\bar{h}_{2}}{\eta}\right\}$ and $g(y(\varphi(x))) \leqslant g\left(h_{2}\right)$ with $0<y(\varphi(x)) \leqslant h_{2}$ and let $\Omega_{2}=\left\{y(\varphi(x)) \in B:\|y(\varphi(x))\|<h_{2}\right\}$.

If $y(\varphi(x)) \in K \cap \partial \Omega_{2}$, then the Lemma 2.7 gives us

$$
\begin{aligned}
\operatorname{Ty}(\varphi(x)) & \leqslant \int_{0}^{1} G_{1}(1, z) b(z) g(y(\varphi(z))) d z+\frac{\beta}{1-\beta \xi} \int_{0}^{1} G_{2}(\xi, z) b(z) g(y(\varphi(z))) d z \\
& \leqslant \int_{0}^{1} G_{1}(1, z)\|b\|_{\infty} g\left(h_{2}\right) d z+\frac{\beta}{1-\beta \xi} \int_{0}^{1} G_{2}(\xi, z)\|b\|_{\infty} g\left(h_{2}\right) d z \\
& \leqslant \lambda\left[\|b\|_{\infty}\left(\int_{0}^{1} G_{1}(1, z) d z+\frac{\beta}{1-\beta \xi} \int_{0}^{1} G_{2}(\xi, z) d z\right)\right] h_{2} \\
& =\lambda M_{2} h_{2} \leqslant h_{2}=\|y(\varphi(x))\| .
\end{aligned}
$$

Hence,

$$
\|\mathrm{Ty}(\varphi(x))\| \leqslant\|y(\varphi(x))\| .
$$

Therefore, Theorem 2.11 and Lemmas 2.9 and 2.15 yield a positive fixed point of $\mathrm{T}$ in $\mathrm{K} \cap\left(\bar{\Omega}_{2} \backslash \Omega_{1}\right)$. Hence for the BVP given by (1.1) exists minimum a positive solution.

Case-III: When $\left(A_{5}\right)$ holds.

Since, $0 \leqslant g^{0+)}<M_{2}^{-1}$, then $\exists, h_{1}>0,0<\lambda_{1}<M_{2}^{-1}$ s.t. $g(y(\varphi(x)))<\left(M_{2}^{-1}-\lambda_{1}\right) y(\varphi(x))$, where $0<y(\varphi(x)) \leqslant h_{2}$ and $x \in[0,1]$.

Now, for $\mathrm{y}(\varphi(\mathrm{x})) \in \mathrm{K} \cap \partial \Omega_{1}$ and $\Omega_{1}=\left\{\mathrm{y}(\varphi(\mathrm{x})) \in \mathrm{B}:\|\mathrm{y}(\varphi(\mathrm{x}))\|<\mathrm{h}_{1}\right\}$, Lemma 2.7 gives

$$
\begin{aligned}
\operatorname{Ty}(\varphi(x)) & \leqslant \int_{0}^{1} G_{1}(1, z) b(z) g(y(\varphi(z))) d z+\frac{\beta}{1-\beta \xi} \int_{0}^{1} G_{2}(\xi, z) b(z) g(y(\varphi(z))) d z \\
& \leqslant \int_{0}^{1} G_{1}(1, z)\|b\|_{\infty}\left(M_{2}^{-1}-\lambda_{1}\right) y(\varphi(z)) d z+\frac{\beta}{1-\beta \xi} \int_{0}^{1} G_{2}(\xi, z)\|b\|_{\infty}\left(M_{2}^{-1}-\lambda_{1}\right) y(\varphi(z)) d z \\
& <\|y(\varphi(x))\| .
\end{aligned}
$$

Hence,

$$
\|\operatorname{Ty}(\varphi(x))\| \leqslant\|y(\varphi(x))\| .
$$

Again, since $M_{1}^{-1}<g_{\infty} \leqslant \infty$, then $\exists \bar{h}_{2}>0, \lambda_{2}>0$ s.t. $g(y(\varphi(x))) \geqslant\left(M_{1}^{-1}+\lambda_{2}\right) y(\varphi(x))$, where, $y(\varphi(x)) \geqslant h_{2}$ and $x \in[\eta, 1]$.

Now, for $h_{2}>\max \left\{2 h_{1}, \frac{\bar{h}_{2}}{\eta}\right\}, \Omega_{2}=\left\{y(\varphi(x)) \in B:\|y(\varphi(x))\|<h_{2}\right\}$ and $y(\varphi(x)) \in K \cap \partial \Omega_{2}$, we have $\min _{\eta \leqslant x \leqslant 1} y(\varphi(x)) \geqslant \eta\|y(\varphi(x))\|=\eta h_{2}>h_{2}$. Hence, the Lemma 2.7 gives

$$
\begin{aligned}
\operatorname{Ty}(\varphi(x)) & \geqslant \int_{\eta}^{1} G_{1}(x, z) b(z) g(y(\varphi(z))) d z+\frac{\beta x}{1-\beta \xi} \int_{\eta}^{1} G_{2}(\xi, z) b(z) g(y(\varphi(z))) d z \\
& \geqslant \int_{\eta}^{1} \eta G_{1}(1, z) m\left(M_{1}^{-1}+\lambda_{2}\right) y(\varphi(z)) d z+\frac{\beta \eta}{1-\beta \xi} \int_{\eta}^{1} G_{2}(\xi, z) m\left(M_{1}^{-1}+\lambda_{2}\right) y(\varphi(z)) d z \\
& \geqslant\left(M_{1}^{-1}+\lambda_{2}\right)\left[\eta^{2} m\left(\int_{\eta}^{1} G_{1}(1, z) d z+\frac{\beta}{1-\beta \xi} \int_{\eta}^{1} G_{2}(\xi, z) d z\right)\right]\|y(\varphi(x))\| \\
& >\|y(\varphi(x))\| .
\end{aligned}
$$

Hence,

$$
\|\mathrm{Ty}(\varphi(x))\| \geqslant\|y(\varphi(x))\|
$$

Therefore, Theorem 2.11 and Lemmas 2.9 and 2.15 yield a positive fixed point of $\mathrm{T}$ in $\mathrm{K} \cap\left(\bar{\Omega}_{2} \backslash \Omega_{1}\right)$. Hence the BVP given by (1.1) exists minimum a positive solution. 
Case-IV: When $\left(\mathrm{A}_{6}\right)$ holds.

In this case, since $M_{1}^{-1}<g_{0+} \leqslant \infty$ and $0 \leqslant g^{\infty}<M_{2}^{-1}$, then same case arises as like Case-III. This completes the proof of the theorem.

Theorem 3.2. If $\left(\mathrm{H}_{1}\right),\left(\mathrm{H}_{2}\right)$, and $\left(\mathrm{H}_{3}\right)$ are fulfilled, then under assumptions $\left(\mathrm{A}_{3}\right)$ and $\left(\mathrm{A}_{7}\right)$ the BVP given by (1.1) has at least two positive solutions.

Proof. According to the assumption $\left(\mathrm{A}_{3}\right)$, we have $\mathrm{g}_{0+}=\infty$, then $\exists 0<\mathrm{h}_{3}<\rho$ s.t. $\mathrm{g}(\mathrm{y}(\varphi(x)))>$ $M_{1}^{-1} y(\varphi(x))$, with $0<y(\varphi(x)) \leqslant h_{3}$ and $x \in[\eta, 1]$.

Now, for $y(\varphi(x)) \in K \cap \partial \Omega_{1}$ and $\Omega_{1}=\left\{y(\varphi(x)) \in B:\|y(\varphi(x))\|<h_{3}\right\}$, Lemma 2.7 gives us

$$
\begin{aligned}
\operatorname{Ty}(\varphi(x)) & >\int_{\eta}^{1} \eta G_{1}(x, z) \mathrm{mM}_{1}^{-1} \mathrm{y}(\varphi(z)) d z+\frac{\beta \eta}{1-\beta \xi} \int_{\eta}^{1} \mathrm{G}_{2}(\xi, z) \mathrm{mM}_{1}^{-1} \mathrm{y}(\varphi(z)) \mathrm{d} z \\
& \geqslant M_{1}^{-1}\left[\eta^{2} \mathrm{~m}\left(\int_{\eta}^{1} \mathrm{G}_{1}(1, z) \mathrm{d} z+\frac{\beta}{1-\beta \xi} \int_{\eta}^{1} \mathrm{G}_{2}(\xi, z) d z\right)\right]\|y(\varphi(x))\|=\|y(\varphi(x))\|,
\end{aligned}
$$

i.e.,

$$
\|\operatorname{Ty}(\varphi(x))\| \geqslant\|y(\varphi(x))\|
$$

Hence, Theorem 2.13 yields $\mathrm{I}\left(\mathrm{T}, \mathrm{K}_{\mathrm{h}_{3}}, \mathrm{~K}\right)=0$.

Again, since $g_{\infty}=\infty$, then $\exists \bar{h}_{4}>\rho$, s.t. $g(y(\varphi(x))) \geqslant M_{1}^{-1} y(\varphi(x))$, where $0<y(\varphi(x)) \geqslant \bar{h}_{4}>0$ and $x \in[\eta, 1]$.

Now, if we set $\mathrm{h}_{4}=\frac{\overline{\mathrm{h}}_{4}}{\eta}, \Omega_{2}=\left\{\mathrm{y}(\varphi(x)) \in \mathrm{B}:\|\mathrm{y}(\varphi(x))\|<\mathrm{h}_{4}\right\}$, then for $\mathrm{y}(\varphi(x)) \in \mathrm{K} \cap \partial \Omega_{2}$, we have $\min _{\eta \leqslant x \leqslant 1} y(\varphi(x)) \geqslant \eta\|y(\varphi(x))\|=\eta h_{4}=\bar{h}_{4}$.

Thus, by Lemma 2.7, we have

$$
\operatorname{Ty}(\varphi(x)) \geqslant M_{1}^{-1}\left[\eta^{2} m\left(\int_{\eta}^{1} G_{1}(1, z) d z+\frac{\beta}{1-\beta \xi} \int_{\eta}^{1} G_{2}(\xi, z) d z\right)\right]\|y(\varphi(x))\|=\|y(\varphi(x))\|,
$$

i.e.,

$$
\|\operatorname{Ty}(\varphi(x))\| \geqslant\|y(\varphi(x))\| .
$$

Thus, Theorem 2.13 yields $\mathrm{I}\left(\mathrm{T}, \mathrm{K}_{\mathrm{h}_{4}}, \mathrm{~K}\right)=0$.

Now, if $\Omega_{3}=\{y(\varphi(x)) \in B:\|y(\varphi(x))\|<\rho\}$, then $y(\varphi(x)) \in K \cap \partial \Omega_{3}$ and assumption (A $\left.A_{7}\right)$ give $g(y(\varphi(x)))<M_{2}^{-1} \rho$, for all $x \in[0,1]$ and hence

$$
\operatorname{Ty}(\varphi(x))<\int_{0}^{1} G_{1}(1, z)\|b\|_{\infty} M_{2}^{-1} \rho d z+\frac{\beta}{1-\beta \xi} \int_{0}^{1} G_{2}(\xi, z)\|b\|_{\infty} M_{2}^{-1} \rho d z \leqslant M_{2}^{-1} M_{2} \rho=\|y(\varphi(x))\| .
$$

This implies that $\|\mathrm{Ty}(\varphi(x))\| \leqslant\|y(\varphi(x))\|$. Hence, Theorem 2.13 gives $I\left(T, K_{\rho}, K\right)=1$. Therefore, $\mathrm{I}\left(\mathrm{T}, \mathrm{K}_{\mathrm{h}_{4}} \backslash \overline{\mathrm{K}}_{\rho}, \mathrm{K}\right)=-1$ and $\mathrm{I}\left(\mathrm{T}, \mathrm{K}_{\rho} \backslash \overline{\mathrm{K}}_{\mathrm{h}_{3}}, \mathrm{~K}\right)=1$. Then applications of Lemma 2.9, Lemma 2.15 and Theorem 2.13, yield that T exists minimum two positive fixed points $y_{1} \in \mathrm{K} \cap\left(\bar{\Omega}_{3} \backslash \Omega_{1}\right)$ and $y_{2} \in \mathrm{K} \cap\left(\bar{\Omega}_{2} \backslash \Omega_{3}\right)$ s.t. $0<\left\|y_{1}\right\|<\rho<\left\|y_{2}\right\|$ and this means that the BVP given by (1.1) exists minimum two positive solutions in $\mathrm{K}$.

Theorem 3.3. If $\left(\mathrm{H}_{1}\right),\left(\mathrm{H}_{2}\right)$ and $\left(\mathrm{H}_{3}\right)$ are fulfilled, then under assumptions $\left(\mathrm{A}_{4}\right)$ and $\left(\mathrm{A}_{8}\right)$ the BVP given by (1.1) exists minimum two positive solutions.

Proof. According to the assumption $\left(\mathrm{A}_{4}\right)$, we have $\mathrm{g}^{0+}=0, \exists$ a positive constant $h_{3}$ s.t. $g(y(\varphi(x))) \leqslant$ $\delta_{2} y(\varphi(x))$, where $0<y(\varphi(x)) \leqslant h_{3}$ and $\delta_{2}>0$. Then for $y(\varphi(x)) \in K \cap \partial \Omega_{1}$ and

$$
\Omega_{1}=\left\{y(\varphi(x)) \in B:\|y(\varphi(x))\|<h_{3}\right\}, T y(\varphi(x))
$$


can be written as

$$
\begin{aligned}
\operatorname{Ty}(\varphi(x)) & \leqslant \int_{0}^{1} G_{1}(1, z)\|b\|_{\infty} \delta_{2} y(\varphi(z)) d z+\frac{\beta}{1-\beta \xi} \int_{0}^{1} G_{2}(\xi, z)\|b\|_{\infty} \delta_{2} y(\varphi(z)) d z \\
& \leqslant \delta_{2}\left[\|b\|_{\infty}\left(\int_{0}^{1} G_{1}(1, z) d z+\frac{\beta}{1-\beta \xi} \int_{0}^{1} G_{2}(\xi, z) d z\right)\right]\|y(\varphi(x))\|=\delta_{2} M_{2}\|y(\varphi(x))\|,
\end{aligned}
$$

i.e.,

$$
\|\mathrm{Ty}(\varphi(x))\| \leqslant\|y(\varphi(x))\| .
$$

Hence, Theorem 2.13 gives $\mathrm{I}\left(\mathrm{T}, \mathrm{K}_{\mathrm{h}_{3}}, \mathrm{~K}\right)=1$.

Again, for $g^{\infty}=0, \exists$ a positive constant $\bar{h}_{4}$ s.t. $g(y(\varphi(x))) \leqslant \delta_{3} y(\varphi(x))$, where $y(\varphi(x)) \geqslant \bar{h}_{4}, \delta_{3}>0$, and $\delta_{3} M_{2} \leqslant 1$. Then Case-II of Theorem 3.1 arises, hence we get

$$
\|\mathrm{Ty}(\varphi(x))\| \leqslant\|y(\varphi(x))\| .
$$

Thus, by an application of Theorem 2.13, we have $I\left(T, K_{h_{4}}, K\right)=1$. Finally, consider a set $\Omega_{3}=$ $\{\mathrm{y}(\varphi(x)) \in \mathrm{B}:\|\mathrm{y}(\varphi(x))\|<\rho\}$, then for any $\mathrm{y}(\varphi(x)) \in \mathrm{K} \cap \partial \Omega_{3}$ the assumption $\left(\mathrm{A}_{8}\right)$ gives $\mathrm{g}(\mathrm{y}(\varphi(x))) \geqslant$ $M_{1}^{-1} \rho$, for $x \in[\eta, 1]$ and hence

$$
\begin{aligned}
\operatorname{Ty}(\varphi(x)) & >\int_{\eta}^{1} \eta G_{1}(x, z) m M_{1}^{-1} \rho d z+\frac{\beta \eta}{1-\beta \xi} \int_{\eta}^{1} G_{2}(\xi, z) m M_{1}^{-1} \rho d z \\
& \geqslant \int_{\eta}^{1} \eta^{2} G_{1}(1, z) m M_{1}^{-1} \rho d z+\frac{\beta \eta^{2}}{1-\beta \xi} \int_{\eta}^{1} G_{2}(\xi, z) m M_{1}^{-1} \rho d z \geqslant M_{1}^{-1} M_{1} \rho=\|y(\varphi(x))\|,
\end{aligned}
$$

i.e.,

$$
\|\mathrm{Ty}(\varphi(x))\|>\|y(\varphi(x))\|
$$

Hence, the Theorem 2.13 gives $I\left(T, K_{\rho}, K\right)=0$. Therefore, $I\left(T, K_{h_{4}} \backslash \bar{K}_{\rho}, K\right)=1$ and $I\left(T, K_{\rho} \backslash \bar{K}_{h_{3}}, K\right)=-1$.

Then applications of Lemma 2.9, Lemma 2.15, and Theorem 2.13, yield that $\mathrm{T}$, there exists at least two positive fixed points $y_{1} \in K \cap\left(\bar{\Omega}_{3} \backslash \Omega_{1}\right)$ and $y_{2} \in K \cap\left(\bar{\Omega}_{2} \backslash \Omega_{3}\right)$ s.t. $0<\left\|y_{1}\right\|<\rho<\left\|y_{2}\right\|$. Thus, the BVP given by (1.1) has at least two positive solutions in $\mathrm{K}$.

\section{Examples}

In this section, we provide some illustrative examples.

Example 4.1. Let us suppose a BVP associated to CFONLDE with an advanced argument in the following way

$$
\left\{\begin{array}{l}
{ }^{C} D_{0^{+}}^{\frac{5}{2}} y(x)+e^{-x} y^{\sigma}(\varphi(x))=0, x \in(0,1), \\
y(0)=0, y^{\prime \prime}(0)=0, y(1)=\beta y(\xi),
\end{array}\right.
$$

wherever, $\sigma>1,0<\xi<1,0<\beta<\frac{1}{\xi}$ and $\varphi(x)=x^{\kappa}, 0<\kappa<1$. Comparing the BVPs given by (4.1) and (1.1), we obtain

$$
g(y)=y^{\sigma}, b(x)=e^{-x}, \text { and } \varphi(x)=x^{k} .
$$

Which fulfilled the hypothesis given by $\left(\mathrm{H}_{1}\right),\left(\mathrm{H}_{2}\right),\left(\mathrm{H}_{3}\right)$ and we get $\mathrm{g}^{0+}=0$ and $\mathrm{g}_{\infty}=\infty$. Therefore, according to Theorem 3.1 with assumption $\left(\mathrm{A}_{1}\right)$ we can say that the BVP given by (4.1) exists minimum a positive solution.

Example 4.2. Let us suppose a BVP associated to CFONLDE with an advanced argument in the following way

$$
\left\{\begin{array}{l}
{ }^{c} D_{0^{+}}^{\frac{5}{2}} y(x)+e^{-x}\left(1+y^{\sigma}(\varphi(x))\right)=0, x \in(0,1), \\
y(0)=0, y^{\prime \prime}(0)=0, y(1)=\beta y(\xi),
\end{array}\right.
$$

wherever, $0<\sigma<1,0<\xi<1,0<\beta<\frac{1}{\xi}$ and $\varphi(x)=x^{k}, 0<\kappa<1$. Comparing the BVPs given by (4.2) 
and (1.1), we get

$$
g(y)=1+y^{\sigma}, b(x)=e^{-x} \text {, and } \varphi(x)=x^{k} .
$$

Which fulfilled the hypothesis given by $\left(\mathrm{H}_{1}\right),\left(\mathrm{H}_{2}\right),\left(\mathrm{H}_{3}\right)$ and we get $\mathrm{g}_{0+}=\infty$ and $\mathrm{g}^{\infty}=0$. Therefore, Theorem 3.1 with assumption $\left(\mathrm{A}_{2}\right)$ confirm that the BVP given by (4.2) has at least one positive solution.

Example 4.3. Let us suppose a BVP associated to CFONLDE with an advanced argument in the following way

$$
\left\{\begin{array}{l}
{ }^{C} D_{0^{+}}^{\gamma} y(x)+e^{\tan x}\left(\lambda \ln (1+y(\varphi(x)))+y^{2}(\varphi(x))\right)=0, x \in(0,1), \\
y(0)=0, y^{\prime \prime}(0)=0, y(1)=\beta y(\xi),
\end{array}\right.
$$

wherever, $2<\gamma \leqslant 3, \lambda>0$ fixed and sufficiently small, $0<\xi<1,0<\beta<\frac{1}{\xi}$ and $\varphi(x)=\chi^{\frac{1}{2}}$. Comparing the BVPs given by (4.3) and (1.1), we yield

$$
g(y)=\lambda \ln (1+y(\varphi(x)))+y^{2}(\varphi(x)), b(x)=e^{\tan x} \text {, and } \varphi(x)=x^{\frac{1}{2}} .
$$

Which fulfilled the hypothesis given by $\left(\mathrm{H}_{1}\right),\left(\mathrm{H}_{2}\right),\left(\mathrm{H}_{3}\right)$ and we obtain $\mathrm{g}^{0+}=\lambda$ and $\mathrm{g}_{\infty}=\infty$. Now, for $\xi=\frac{1}{2}, \beta=1, x=\frac{1}{2}, \gamma=\frac{5}{2}, \eta=\frac{1}{2}$, we have $0 \leqslant g^{0+}<M_{2}^{-1}, M_{1}^{-1}<g_{\infty} \leqslant \infty$. Therefore, according to Theorem 3.1 with assumption $\left(\mathrm{A}_{5}\right)$ we can say that the BVP given by (4.3) has at least one positive solution.

Example 4.4. Let us suppose a BVP associated to CFONLDE with an advanced argument in the following way

$$
\left\{\begin{array}{l}
{ }^{c} D_{0^{+}}^{\gamma} y(x)+e^{-x}\left(y^{2}(\varphi(x)) e^{-y(\varphi(x))}+\delta(\sin y(\varphi(x)))\right)=0, x \in(0,1), \\
y(0)=0, y^{\prime \prime}(0)=0, y(1)=\beta y(\xi),
\end{array}\right.
$$

wherever, $2<\gamma \leqslant 3, \delta>0$ fixed and sufficiently large, $0<\xi<1,0<\beta<\frac{1}{\xi}$ and $\varphi(x)=x^{\frac{1}{2}}$. Comparing the BVPs given by (4.4) and (1.1), we obtain

$$
g(y)=y^{2}(\varphi(x)) e^{-y(\varphi(x))}+\delta(\sin y(\varphi(x))), b(x)=e^{-x}, \text { and } \varphi(x)=x^{\frac{1}{2}} .
$$

Hence, it is clear that hypothesis $\left(\mathrm{H}_{1}\right),\left(\mathrm{H}_{2}\right),\left(\mathrm{H}_{3}\right)$ are satisfied and we get $\mathrm{g}_{0+}=\delta$ and $\mathrm{g}^{\infty}=0$. Now, if we take $\xi=\frac{1}{2}, \beta=1, x=\frac{1}{2}, \gamma=\frac{5}{2}, \eta=\frac{1}{2}$, then it is easy to shown that $M_{1}^{-1}<g_{0+} \leqslant \infty$ and $0 \leqslant g^{\infty}<M_{2}^{-1}$. Therefore, according to Theorem 3.1 with assumption $\left(\mathrm{A}_{6}\right)$ we can say that the BVP given by (4.4) has at least one positive solution.

Example 4.5. Consider a BVP associated to CFONLDE with an advanced argument as follows

$$
\left\{\begin{array}{l}
{ }^{C} D_{0^{+}}^{\gamma} y(x)+y^{v}(\varphi(x))+y^{w}(\varphi(x))-1=0, x \in(0,1), \\
y(0)=0, y^{\prime \prime}(0)=0, y(1)=\beta y(\xi)
\end{array}\right.
$$

wherever, $2<\gamma \leqslant 3,0<\xi<1,0<\beta<\frac{1}{\xi}$ and $\varphi(x)=x^{\frac{1}{2}}$. From the BVP given by (4.5), we obtain

$$
g(y)=y^{v}(\varphi(x))+y^{w}(\varphi(x))-1, b(x)=1, \text { and } \varphi(x)=x^{\frac{1}{2}} .
$$

Which fulfilled the hypothesis given by $\left(\mathrm{H}_{1}\right),\left(\mathrm{H}_{2}\right),\left(\mathrm{H}_{3}\right)$. Now, taking $v \in(0,1), w>1, \xi=\frac{1}{2}, \beta=\frac{3}{2}, x=$ $\frac{1}{2}, \gamma=\frac{5}{2}, \eta=\frac{1}{2}$, we get $g_{0+}=\infty, g_{\infty}=\infty$ and $g(y(\varphi(x)))<M_{2}^{-1} \rho, 0<y(\varphi(x)) \leqslant \rho$, where $\rho=1$. Therefore, according to Theorem 3.2 with assumptions $\left(\mathrm{A}_{3}\right)$ and $\left(\mathrm{A}_{7}\right)$, we can say that the BVP given by (4.5) has at least two positive solutions $y_{1}, y_{2}$ and $0<\left\|y_{1}\right\|<1<\left\|y_{2}\right\|$.

Example 4.6. Consider a BVP associated to CFONLDE with an advanced argument as follows

$$
\left\{\begin{array}{l}
{ }^{C} D_{0^{+}}^{\gamma} y(x)+y^{-v}(\varphi(x))+y^{-w}(\varphi(x))+1=0, x \in(0,1), \\
y(0)=0, y^{\prime \prime}(0)=0, y(1)=\beta y(\xi)
\end{array}\right.
$$

wherever, $2<\gamma \leqslant 3,0<\xi<1,0<\beta<\frac{1}{\xi}$ and $\varphi(x)=x^{\frac{1}{2}}$. From the BVP given by (4.6), we get 


$$
g(y)=y^{-v}(\varphi(x))+y^{-w}(\varphi(x))+1, b(x)=1, \text { and } \varphi(x)=x^{\frac{1}{2}} .
$$

Which fulfilled the hypothesis given by $\left(\mathrm{H}_{1}\right),\left(\mathrm{H}_{2}\right),\left(\mathrm{H}_{3}\right)$. Now, taking $v \in(0,1), w>1, \xi=\frac{1}{2}, \beta=\frac{3}{2}, x=$ $\frac{1}{2}, \gamma=\frac{5}{2}, \eta=\frac{1}{2}$, we get $g^{0+}=0, g^{\infty}=0$ and $g(y(\varphi(x)))>M_{1}^{-1} \rho, \rho<y(\varphi(x)) \leqslant \frac{\rho}{\beta}$, where $\rho=1$. Therefore, according to Theorem 3.3 with assumptions $\left(\mathrm{A}_{4}\right)$ and $\left(\mathrm{A}_{8}\right)$, we can say that the BVP given by (4.6) has at least two positive solutions $y_{1}, y_{2}$ and $0<\left\|y_{1}\right\|<1<\left\|y_{2}\right\|$.

\section{Conclusion}

In this study, we established the general principles for checking presence and diversity of positive solutions to a BVP given by (1.1). Here, we applied Guo-Krasnoselskii's fixed point theorem and Fixedpoint index theory to prove our main results. By an application of Theorem 3.1, one may check the presence of minimum a positive solution of BVP given by (1.1), whereas the Theorems 3.2 and 3.3 may be used to cheek the presence of minimum two positive solutions to that BVP. The results of this article provided easy and straightforward techniques to cheek the presence and diversity of positive solutions to the CFONLDE with an advanced argument. Furthermore, outcomes of this article extended the equivalent results of Jankowski [24], Ntouyas et al. [31], Rizqan and Dhaigude [33], and Wang et al. [37]. Finally, we verified our main results by some particular examples. In the conceivable future we propose to study the possibility of extending the results of this paper by replacing the Caputo's fractional derivative with Riemann-Liouville fractional derivative occurring in the BVP given by (1.1) using integral BVCs and/or the infinite-point BVCs in place of three-point BVCs.

\section{Acknowledgment}

The authors would like to thank to the referees for their valuable comments and suggestions. The second author also gratefully acknowledges the partial support this research work by the Fundamental Research Grant Scheme (FRGS) having project number 5524674.

\section{Authors contributions}

Md. Asaduzzaman: Conceptualization, Methodology, Writing- Original draft preparation. Adem Kilicman: Visualization, Investigation, Formal analysis, Writing-Reviewing and Editing. Md. Zulfikar Ali: Supervision, Validation.

\section{References}

[1] H. Afshari, M. Sajjadmanesh, D. Baleanu, Existence and uniqueness of positive solutions for a new class of coupled system via fractional derivatives, Adv. Differ. Equ., 2020 (2020), 18 pages. 1

[2] R. P. Agarwal, D. O’Regan, S. Staněk, Positive solutions for Dirichlet problems of singular nonlinear fractional differential equations, J. Math. Anal. Appl., 371 (2010), 57-68. 1

[3] R. P. Agarwal, D. O'Regan, P. J. Y. Wong, Positive Solutions of Differential, Difference and Integral Equations, Springer, Dordrecht, (1999). 1

[4] B. Ahmad, J. J. Nieto, Existence results for a coupled system of nonlinear fractional differential equations with three-point boundary conditions, Comput. Math. Appl., 58 (2009), 1838-1843. 1

[5] M. Asaduzzaman, M. Z. Ali, Existence of positive solution to the boundary value problems for coupled system of nonlinear fractional differential equations, AIMS Math., 4 (2019), 880-895. 1

[6] M. Asaduzzaman, A. Kilicman, M. Z. Ali, S. H. Sapar, Fixed point theorem based solvability of 2-Dimensional dissipative cubic nonlinear Klein-Gordon equation, Math., 8 (2020), 1103. 1

[7] A. Augustynowicz, H. Leszczyński, W. Walter, On some nonlinear ordinary differential equations with advanced arguments, Nonlinear Anal., 53 (2003), 495-505. 1

[8] Z. Bai, On positive solutions of a nonlocal fractional boundary value problem, Nonlinear Anal., 72 (2010), 916-924. 1

[9] S. Banaei, M. B. Ghaemi, R. Saadati, An extension of Darbo's theorem and its application to system of neutral differential equations with deviating argument, Miskolc Math. Notes, 18 (2017), 83-94. 1 
[10] T. A. Burton, Differential inequalities for integral and delay differential equations, Comparison Methods and Stability Theory: Lecture Notes in Pure and Appl. Math., Dekker, New York, (1994). 1

[11] Y.-K. Chang, J. J. Nieto, Some new existence results for fractional differential inclusions with boundary conditions, Math. Comput. Model., 49 (2009), 605-609. 1

[12] H. Chen, S. Kang, L. Kong, Y. Gao, Existence of Three Positive Solutions for a Class of Boundary Value Problems of Caputo Fractional q-Difference Equation, Discrete Dyn. Nat. Soc., 2018 (2018), 9 pages. 1

[13] Y. Cu, W. Ma, Q. Sun, X. Su, New uniqueness results for boundary value problem of fractional differential equation, Nonlinear Anal. Model. Control, 23 (2018), 31-39. 1

[14] F. H. Damag, A. Kiliçman, A. T. Al-Arioi, On hybrid type nonlinear fractional integrodifferential equations, Mathematics, 8 (2020), 14 pages. 1

[15] F. H. Damag, A. Kilicman, H. Dutta, R. W. Ibrahim, A Note on the Lower and Upper Solutions of Hybrid-Type Iterative Fractional Differential Equations, Natl. Acad. Sci. Lett., 43 (2020), 277-281. 1

[16] K. Deimling, Nonlinear Functional Analysis, Springer, Berlin, (1985). 1, 2, 2, 2

[17] A. Devi, A. Kumar, D. Baleanu, A. Khan, On stability analysis and existence of positive solutions for a general non-linear fractional differential equations, Adv. Differ. Equ., 2020 (2020), 16 pages. 1

[18] W. G. El-Sayed, Solvability of a neutral differential equation with deviated argument, J. Math. Anal. Appl., 327 (2007), 342-350. 1

[19] M. Fréchet, Sur quelques points du calcul fonctionnel, Rend. Circ. Mat. Palermo, 22 (1906), 1-72.

[20] C. S. Goodrich, Existence of a positive solution to a class of fractional differential equations, Appl. Math. Lett., 23 (2010), 1050-1055. 1

[21] D. Guo, V. Lakshmikantham, Nonlinear Problems in Abstract Cones, Notes and Reports in Math. Sci. Eng., Academic Press, Boston, (1988). 1, 2

[22] C. P. Gupta, Solvability of a three-point nonlinear boundary value problem for a second order ordinary differential equation, J. Math. Anal. Appl. 168 (1992), 540-551. 1

[23] T. Jankowski, Solvability of three-point boundary value problems for second order differential equations with deviating arguments, J. Math. Anal. Appl., 312 (2005), 620-636. 1

[24] T. Jankowski, Fractional differential equations with deviating arguments, Dyn. Syst. Appl., 17 (2008), 677-684. 1, 5

[25] T. Jankowski, Positive solutions for three-point one-dimensional p-Laplacian boundary value problems with advanced arguments, Appl. Math. Comput., 215 (2009), 125-131. 1

[26] T. Jankowski, Positive solutions for fourth-order differential equations with deviating arguments and integral boundary conditions, Nonlinear Anal., 73 (2010), 1289-1299. 1

[27] A. A. Kilbas, H. M. Srivastava, J. J. Trujillo, Theory and Applications of Fractional Differential Equations, Elsevier Science B.V., Amsterdam, (2006). 1, 2

[28] V. Lakshmikantham, S. Leela, J. V. Devi, Theory of Fractional Dynamic Systems, Cambridge Academic Publishers, Cambridge, (2009). 1

[29] R. Ma, Multiplicity of positive solutions for second-order three-point boundary value problems, Comput. Math. Appl., 40 (2000), 193-204. 1

[30] J. J. Nieto, Maximum principles for fractional differential equations derived from Mittag-Leffler functions, Appl. Math. Lett., 23 (2010), 1248-1251. 1

[31] S. K. Ntouyas, G. Wang, L. Zhang, Positive solutions of arbitrary order nonlinear fractional differential equations with advanced arguments, Opuscula Math., 31 (2011), 433-442. 1, 5

[32] I. Podlubny, Fractional Differential Equations, Academic Press, San Diego, (1999). 1, 2

[33] B. H. Rizqan, D. B. Dhaigude, Positive solutions of nonlinear fractional differential equations with an advanced argument under integral boundary value conditions, Indian J. Math., 60 (2018), 491-507. 1, 5

[34] Q. Sun, H. Ji, Y. Cui, Positive Solutions for Boundary Value Problems of Fractional Differential Equation with Integral Boundary Conditions, J. Funct. Spaces, 2018 (2018), 6 pages. 1

[35] Y. Sun, L. Liu, J. Zhang, R. P. Agarwal, Positive solutions of singular three-point boundary value problems for second-order differential equations, J. Comput. Appl. Math., 230 (2009), 738-750. 1

[36] F. J. Torres, Existence of positive solutions for a boundary value problem of a nonlinear fractional differential equation, Bull. Iranian Math. Soc., 39 (2013), 307-323. 1

[37] G. Wang, S. K. Ntouyas, L. Zhang, Positive solutions of the three-point boundary value problem for fractional-order differential equations with an advanced argument, Adv. Differ. Equ., 2011 (2011), 11 pages. 1, 1, 5

[38] J. R. L. Webb, Positive solutions of some three-point boundary value problems via fixed point index theory, Nonlinear Anal., 47 (2001), 4319-4332. 1

[39] X. Xu, Multiplicity results for positive solutions of some semi-positone three-point boundary value problems, J. Math. Anal. Appl., 291 (2004), 673-689. 1

[40] C. Yang, C. Zhai, J. Yan, Positive solutions of the three-point boundary value problem for second order differential equations with an advanced argument, Nonlinear Anal., 65 (2006), 2013-2023. 1, 2 